\title{
Globalization and youth: philosophical analysis of challenges and ways to overcome them
}

\author{
Natalia A. Orekhovskaya - Alexander A. Galushkin - Elena V. Maleko - \\ Tatyana A. Bezenkova - Natalya A. Plugina
}

DOI: $10.18355 / X L .2018 .11 .02 .20$

\begin{abstract}
Philosophical analysis of the issues concerning acceleration of the modern civilization development, high dynamics of international life, strengthening of interrelation and interdependence of peoples and states, is especially relevant for professionals studying contemporary society in general, and youth in particular. The dual purpose of the research study is to focus on the definition of the concept of 'globalization', because there is no well-established precise definition in scientific practice, and both Western European and Russian researchers offer their own interpretations for this concept; and to study the ambiguity of the social effects of globalization, which has generated both supporters and fierce opponents of this phenomenon. The study keynote is provided through the social-and-philosophical analysis of the impact of globalization, especially on young people, as well as highlighting the current challenges facing young people today and developing new value orientations. The author proceeds from the data obtained in the sociological research conducting the scientific literature review and students' group and in-depth interviews in Russian universities. The analytical work made it possible to propose some steps in overcoming the challenges of globalization, and the author comes to a conclusion about the need to undertake a further large-scale study of the globalization process. The materials of the paper may be useful to researchers, as well as teachers and professionals involved in the education of young people.
\end{abstract}

Key words: globalization, philosophical analysis of globalization, cultural globalization, ways to fight globalization, young people, internet

\section{Introduction}

Dynamism and acceleration, mobility and increasing flow of information are the defining characteristics of modern life. These features penetrate and connect not only people's daily lives but also the lives of entire states. We can easily move anywhere in the world, and smart phones give us access to expert-level advice service and information. Moreover, we are able to convey emotions using emoticons when we communicate with foreigners and don't speak their language, and loss of the mobile phone causes our panic. These examples can be continued and continued, and prove that globalization increasingly impacts aspects of our scientific and everyday life.

Scientists offer several options for the interpretation of this term. For example, German sociologist U. Beck (2001) analyses globalization as a multi-dimensional process: economic, social, political, cultural, technological, and ecologic. For him, an obvious outcome of the industrial modernity success has been connected with its ability to cross borders and infiltrate cultures; though, globalization is not a benign process as it challenges the territoriality and sovereignty of the nation-state, and reduces the authority of the state and its citizens to act unilaterally or independently. He treats it as the inability of the countries to fence off from each other. In this regard, the political and economic interconnection of world society is accompanied by a clash of different value and virtue cultures, a clash of different economic, political and cultural forms of interaction (Beck, 2001).

A British researcher A. Giddens (2004) perceives globalisation as an unpredictable, destabilizing process. Local cultures and traditions are exposed to new cultures and 
ideas, which often means that traditional ways of acting come to be questioned. As a result of globalization, societies and cultures go through a process of detraditionalization, where routine day to day life becomes less and less informed by 'tradition for the sake of tradition'. So, he considers globalization as a multifaceted process combining many factors, the development of which proceeds with contradictions and sometimes in opposite directions. Most people perceive this process as a non-appeal interception of powers and influences from local communities and states with their transfer to the planetary level. In reality, this is only one of the results of globalization. It is a common knowledge that some economic powers have been lost by sovereign states, and there a lot of discussions that globalization is associated with the opposite effect as well (Giddens, 2004). The globalization is the reason for the revival of local cultural identities in different parts of the world. A. Giddens (2004) gives a very clear explanation: if one asks why the Scots want more independence in the UK, or why there is a strong separatist movement in Quebec, the answer is not to be found only in their cultural history; local nationalisms spring up as a response to globalizing tendencies. Russian sociologist L.E. Grinin (2005) defines 'globalization' as an extension of the dependence of the world and all its social phenomena on all its consituents and connectivity with all its subjects, or constituents. Despite the fact that the concept is certainly one of the most contested topics in the social sciences, and - possibly because it is a complex and multifaceted phenomenon - there is not complete unanimity as to the essence and consequences of this largescale process - or rather, set of processes in all spheres of social reality, which will bring both new opportunities and new threats for humankind, because the opportunities of globalization do not come without risks (Samygin et al., 2016).

Economic, political and cultural globalization is ambiguous in its social consequences, and for this reason, we can discuss its supporters and fierce opponents. One of those who argue against is P.S. Gurevich (2009). His point of view is as follows: the form in which globalization is realized today carries a powerful destructive potential and poses a significant danger to the existence and social wellbeing of all segments of society, leading it to the condition of anomie (Gurevich, 2009).

There is no doubt that the anomie is an inevitable consequence of the global transformation of processes in society. Changes occur in the underlying norms, values, and orientations of the youth. The support that can only be provided by profound social-and-cultural relations is lost (Shapovalova, 2015).

It is fair to say that such interdependencies as the general environmental threat, the problem of planetary security, the global information field, the unification of economic and communication spheres, political and cultural influence, are the main features of globalization. According to U. Beck (2001) globalism involves the idea of the world market: the growth of the world market leads to far-reaching consequences and will be reflected in cultures, identities, and lifestyles. He stresses that the main problem of cultural globalization is the lack of a common vision of whether it will lead to a common culture or create new differences between national cultures.

It is impossible to ignore the fact that the technology, which has progressed enormously in every field imaginable at the end of the XX century, in fact, violated the principle of locality and isolation of cultures. As a result, a new systemic quality a global universal culture - has emerged, relationships between different countries and peoples have improved. Crisis and anti-cultural phenomena occurring in one sector of the civilization are reflected in its other regions. At the same time, we can oversee an intense global interaction, when culture samples, scientific achievements, art, and new forms of social or political life are translated and assimilated in a relatively short time throughout the entire civilization. That is, culture mergers and acquisitions, as well as transplantation of culture, is achieved through improving

XLinguae, Volume 11, Issue 2, April 2018, ISSN 1337-8384, eISSN 2453-711X 
communication links. The result is that it forms the causes for people to reject their own culture, its norms, and traditions, loss of civilizational identity that determines the change of value paradigm (Shvatchkina, Igosheva, Polozhenkova, 2016).

A number of researchers believe that today the Western-style economic rationality begins to dominate. They distinguish and identify Americanization and Europeanization in culture. This aspect is associated with cultural expansion, which threatens to lose national identity in most states. This process creates a potential for the emergence of a cosmopolitan identity, a cosmopolitan worldview around the world, which manifests itself more actively among young people than among representatives of other demographic groups.

The philosophical analysis of globalization can be summarized as follows:

- First, the process of globalization is characterized by the recognition and acceptance of the common destiny of mankind and the existence of a common vector in the development. This thesis, though carefully considered, does not seem obvious because, in philosophy, there have been many examples discussed related to nations' and civilization's independent development ideas; suffice it to recall a Russian thinker N.Ya. Danilevsky, a German historian and philosopher Oswald Spengler and an English historian A.A. Toynbee (2002) (Orekhovskaya et al., 2017a, 2017b).

- Secondly, the process of globalization has most often been defined and embodied in the historical development of one or more groups of people united as nations and states, i.e. who identify with each other based on similarities such as common ancestry, language, society, culture or nation, and easily justify the superiority of one group over others.

- Thirdly, the common destiny of mankind is seen not globally as a natural result of the development of different civilizations, but selectively, with a strong influence of political factors.

\section{Hypothesis}

Global changes and challenges that emerged in the last quarter of the twentieth century and manifested themselves at the beginning of the twenty-first century introduced new demands for the functioning of the state, political systems, and interaction of the state and society. It is the processes of globalization, understood as changes in the social, political, economic and cultural spheres familiar to the majority of states that can generally be perceived as the main path for human development. Understanding the direction and nature of this path can help to form new principles of interaction between the society and the state and build effective individual political trajectories of states in the progressive advance of mankind.

In many ways, that is the reason why globalization, as a process and as a result, has been attracting the attention of philosophers for decades. The strengthening of links formed due to the development of a variety of global processes, especially telecommunications, has made many researchers to describe the dynamics of globalization as the creation of the "global village," claiming to form a cosmopolitan global society of the future (Held, 1995), and different perspectives of world society have been discussed.

Other scholars portray globalization as the means for producing new types of discrimination and exploitation - economic, racial, environmental and others. Globalization from this point of view is being considered as an era of 'global apartheid' (Hardt, Negri, 2000).

A different perspective on the idea is expressed by the supporters of a 'Global Empire' theory, which is sometimes associated with a new geopolitical configuration headed by the United States, but can be understood more broadly as a process of homogenizing the world community on the principles of western culture and the capitalist community (Ferguson, 2005; Balakrishnan, 2003). 


\section{Research methodology}

In philosophical disputes about globalization, the question has arisen concerning how young people assess globalization, and what they think about it. The author used three methods to obtain the truest response:

- the content review of the scientific and periodical literature on the topic studied;

- proving the primary sociological data presented by the results obtained during the focus group interviews, a group interview (N-3), students of Russian universities that also underwent in-depth interviewing $(\mathrm{N}-17)$; the study involved teenagers and young people aged 17 to 23 ;

- the secondary sociological data analysis obtained from the All-Russian Public Opinion Research Center, Institute of Sociology of Russian Academy of Sciences, and Federal Government Statistical Service.

\section{Results}

The introduction of information technologies into manufacturing industry and the subsequent technical revolution led to an increase in the introduction of smart techniques into various industries. The technological revolution in such industries as microelectronics, computer science, pharmaceuticals and a number of others has accelerated the transition of European countries from the old industrialism to the industrial development stage. The knowledge economy requires an increase in the level of education, skills, and competences of the labor force because the knowledge had become a crucial resource for the production and competitiveness of goods on world markets. In particular, the European Round Table of Industrialists (ERT), a forum bringing together around 50 Chief Executives and Chairmen of major multinational companies of European parentage covering a wide range of industrial and technological sectors, in 1989, published the report Education and Competence in Europe where they stressed industrial corporations' attitude to education and training as strategic investments vital for their future prosperity (Zhivotovskaya, 2003).

Since the late 70 s of the last century, the need for training and employing highly qualified specialists has generated rapid growth in demand for higher education in European countries.

The students' interview results showed that, first of all, the respondents had difficulties in giving a precise definition of globalization as a term and concept. Typical answers were like the following: expansion and blurring national boundaries; the close interweaving of economic ties; common payment system. Answering the question of what they consider to be the most striking manifestations of globalization, the bulk of the respondents highlighted the significance of information technology and English promoted as a global language of communication. In addition, $90 \%$ of the survey participants admitted that they spoke English more or less fluently, $43 \%$ said that they could communicate freely, and $17 \%$ said they could speak two foreign languages. All respondents were engaged in improving their skills in the foreign languages. About half of them use English every day, communicate on social networks or search on the Internet for help with homeworking.

Information about the users' internet activity correlates with the weekly results of the Public Opinion Fund. Russian young adults gave an affirmative answer to the question about recent having used the web: $60 \%$ had used the day before, $67 \%$ had used the other day, and $70 \%$ have been using it during the month. (Public Opinion Fund, 2017). According to sociological research conducted by Ye.V. Reutov and T.V. Troshina (2015), about $90.8 \%$ of our citizens aged 15 to 24 years and $73.8 \%$ of $25-39$ year-old Russians go online every day. According to the authors of the study, $48 \%$ of the web users believe that it provides them with the most complete and objective information about events in society and the world (Reutov, Troshina, 2015).

XLinguae, Volume 11, Issue 2, April 2018, ISSN 1337-8384, eISSN 2453-711X 
There is evidence of an overwhelming interest in Internet among young people. Young people are absolutely sure that this web penetration into person's everyday life and professional activities is a natural state. The Internet is also popular because it opens up great opportunities in one's desire to escape from reality and build your own virtual world where you can do whatever you want. Youth agile mind is easy to manipulate, that is why young people often create negative perceptions of real life, it is their 'reality distortion field' and eventually they have no critical attitude to any information at all.

The similar conclusions have been made in the papers of I.S. Shapovalova (2015). She also believes that, unfortunately, the Internet has been transformed from an important information source into an alternative reality. Moreover, judging from the content that is the most popular among young people, this reality is often antagonistic and unmanageable. The power of this virtual synergy, its communicative infinity, and accessibility, often compensatory, and self-realization opportunities create the illusion of pervasive advantages of a non-existent, or fake, universe over the real one. Ant what is absolutely shocking, then they feel it vital to follow its laws and slogans" (Shapovalova, 2015).

Most respondents are not afraid of the threat of losing their national identity. Some of them are not afraid to stop feeling Russian. For them, the absence of borders and restrictions is a more valuable fact. Many of them justify their position by blurring the boundaries between musical subcultures and dispelling their hatred for those who are fond of other musical styles.

Hence, the question arises as to what the factor are that unite young people. Most often, young people speak about the opportunity to resist the older generation, which has lost their trust and credibility. Teenagers are convinced that adults are not interested in their opinion; they only teach and impose their position and attitude to life. This is the motivation for them to go online. There they find a chance to speak to, find common ground, and don't have to listen to the adults' 'empty rhetoric'.

The answers to the questions of Russian students about patriotism are particularly alarming because traditionally this group of questions has always been highly appreciated. Young people believe that in modern national history there are no facts that deserve to be proud of. And they consider our past achievements - the conquest of space, the Victory in the 1941-1945 Great Patriotic War, etc. - as events in the distant past and not deserving remembering. Though the overwhelming majority of respondents participated in school celebrations dedicated to the Great Victory Day, deep in their minds, they did not have any inner conviction that it is of importance for them. Today's young people are guided by those who have managed to realize their own ideas and earn money, but not on the heroes who sacrificed themselves in the name of peoples' lives and some universal ideals.

The primary challenge of globalization is to change the consciousness of both European and Russian youth. This tendency is apparent in the society transformation process. We can oversee substitution of fundamental values and attitudes in the minds and souls of the young Russians. Updated and internationally recognized targets, or beacons, guiding the youth to success (for example, in education) are being developed under the pressure of the globalization.

Today it is clear that the 'knowledge economy' needs to create a new concept and model of education that would meet needs of high-tech manufacturing processes and take into account the unique development of society in the context of globalization. The key to a successful education system is a lifelong learning perspective, which is becoming increasingly important, not only as a key organizing principle for all forms of education and learning but also as an absolute necessity for everyone. Developing transition goals and objectives that reflect the content of education programs at all levels is a necessity that is to be successfully converted into reality. A radical restructuring of the conventional organization and institutional structure in the 
education system, from pre-school education to university, postgraduate and development professional training, as well as adult education, is currently an urgent issue in the country. According to experts, the introduction of the new system will stimulate the interaction of various educational structures and creation of a training network, which will involve all formal and informal, public and private educational institutions.

Today, most European countries are engaged into reforms and developing public policies and strategies concerning national education focused precisely on creating a system of continuing education. This has been claimed in the official EU documents related to the problems of education in Europe and the creation of the Europe of Knowledge, comprising the European Higher Education Area and the European Research; they claimed that it must be a Europe of Knowledge in order to prosper and develop (Halliday, 1999).

\section{Discussions}

Globalization has challenged all countries. Today, almost the whole world is involved in this process. Now, there is an urgent need for the international community to join efforts in finding the ways of overcoming negative consequences of globalization.

Sociologist U. Beck (2001) considers educational system must give citizens the opportunity to master the guidelines and abilities that will allow them to understand the contradictions arising in the world community and transnational landscapes. The scientist sees the 'great political response to globalization' in creating and improving the society of educated and intelligent individuals. He believes that the time for education should be extended and it is necessary to weaken or eliminate the binding of studies to specific professions and jobs, focusing the process of training professionals on essential skills and using them as widely as possible. He defined schooling as the provision of credentials leading to individualized career opportunities in the labor market.

This is not just flexibility and lifelong learning, but also the ability to not be afraid of conflicts and to function in a team, acquire social competence, multi-level thinking, understanding of culture, willingness to overcome uncertainty and face the paradox of the second modernity (Beck, 2001).

This is one of the best ways to overcome the challenge of globalization to date. At the present stage of society development, building relationships with young people from the position of 'teacher-student' is doomed to failure. Young people need sensitive and understanding mentors-partners. Respondents admitted that they expect honest assessments and respect for their points of views, even if they are wrong. The teacher should not hesitate to learn from his students. Young people, for example, are more likely to learn computer technology. The process of mutual learning will only contribute to the restoration of trust in elders.

Flexible assimilation of the prescribed norms for young people in the era of individualization is no longer a sufficient level, that's what the prominent philosopher and sociologist I.M. Ilyinsky (2002) believes in. Today it is necessary to form your own 'self' as an active orientation center. It is necessary to teach young people how to live in this world relying only on themselves and counting only on their own forces (Ilyinsky, 2002). The relevance of educating the new generation capable to cooperate, appreciating universal values, and able to overcome the challenges of globalization and benefitting from them personally and their country as well, is indisputable.

\section{Conclusion}

The impact of globalization goes far beyond economics and finance. With the development of information and communication networks and creating of a single 
information field, it will prevail in a powerful factor that affects all aspects of the life of European countries, transforming the social and individual behavior of citizens.

The real impact of the globalization challenges of the second half of the twentieth century was reflected in the fact that a large number of countries in the world were forced to carry out reforms to increase and prove the effectiveness of interaction between the state and society. It is at this time, by the way, that the very idea of effective public administration arises, in many respects, from the practice of wellfunctioning business organizations.

Each country had, of course, its own unique circumstances, making such reforms necessary, but the reforms also were caused by a number of reasons common to different states, and these reasons are global in nature. Among these reasons, it is necessary to point out the changes in the interaction of the state and society, which took place throughout the twentieth century, and, by the second half of it, became irreversible and innovative in nature; in addition, these objectively and subjectively occurring conscious changes imposed changes in the political - administrative structure of the world order, which occurred in the late $80 \mathrm{~s}$ and early $90 \mathrm{~s}$ in connection with the destruction of the socialist system and the disappearance of the USSR. We must not forget the purely economic causes associated with the will to stop the growth in the appreciation of maintaining state power, minimizing the losses caused to businesses and the economy as a whole by abuses of public service employees (corrupt).

Thus, first, the political reformers - administrative systems in various countries - in the last 30 years have proven to reduce the role of the nation-state by transferring its functions, on the one hand, to the interstate level, and on the other hand, to the lower level starting from the government agencies and finishing with municipal offices (Evstifeev, 2007; Evstifeev, 2010 ). This resulted in the emergence of new methods of administrative and political management, fragmenting of the public sector, the reduction of the public service responsibilities and creation of new conditions in organizing and managing the society.

Second, raising the overall level of education is now being considered as an economic imperative. Countries not investing in higher education, research and development of lifelong learning may be marginalized. Modern world education understanding as 'commonweal' and 'public good' is coming back enriched with the idea that the level of education development is closely interrelated with the welfare of society.

\section{Acknowledgements}

The publication has been prepared with the support of the "RUDN University Program 5-100".

\section{Bibliographic references}

BECK, U. 2001. What is globalization? Moscow: Progress-Tradition. ISBN 5-89826109-5

GRECMANOVA, H. - DOPITA, M. - URBANOVSKA, E.. 2017. Ethical aspects of communication in the academic environment. In: Communications, Vol. 19, n. 1, pp. 25-29. ISSN 1335-4205.

EVSTIFEEV, R.V. 2007. Public Administration as a Subject of Political Science: Reflections at the Entrance Item. In: Proceedings of the 5th international conference of the Faculty of Public Administration. Moscow: MSU. ISBN 978-5-317-02834-3

EVSTIFEEV, R.V. 2010. State and Society in the XXI century: Globalization of Metaphor and Metaphor of Globalization. In: Community and Power, vol. 25, n. 1, pp. 4-9. ISSN: 1996-0522

FERGUSON, N. 2005. Colossus: The Price of America's Empire. New York: Penguin Press. ISBN-13: 978-0143034797 ISBN-10: 0143034790 
GIDDENS, A. 2004. Runaway World: How Globalization is Reshaping Our Lives. Moscow: Publishing House "Ves Mir". ISBN 5-7777-0304-6.

GONDA, D. - EMANOVSKY, P. 2017. The contribution of learning logic to ethical decision making. In: Communications, Vol. 19, n. 1, pp. 126-130. ISSN 1335-4205.

GRININ, L.E. 2005. On the Brink of Centuries: New Processes. In: Community and Power, n.1, pp. 6-31. ISSN 1811-7481

GUREVICH, P.S. 2009. Image of Russia in the Process of Globalization. In: Globalization Age, n. 2, pp. 178-191. ISSN: 1994-9065

HALLIDAY, F. 1999. The chimera of the «International University». In: Intern. Affairs, vol. 75, n. 1, pp. 99-120. ISSN 0020-5850

HARDT, M. - NEGRI, A. 2000. Empire. Cambridge: Harvard University Press. Moscow: Practis. ISBN 5-9O1S74-4O-O.

HELD, D. 1995. Democracy and the Global Order: From the Modern State to

Cosmopolitan Governance. Stanford: Stanford University Press. ISBN: 9780804726863.

ILYINSKY, I.M. 2002. Educational revolution. Moscow: MGSA. ISBN: 1998-9873: 2218-9238.

OREKHOVSKAYA, N.A. - TYURIKOV, A.G. - RAZOV, P.V. - KIBAKIN, M.V.

- Kiseleva, N.I. 2017a. Student Youth Tolerance as a Factor of Socio-Cultural Integration. In: Eurasian Journal of Analytical Chemistry, vol. 1297b, 1283-1289. ISSN: 1306-3057

OREKHOVSKAYA, N.N. - LISITZINA, T.B. - BEZBORODOVA, L.A. POPOVA, O.V. - GAZIZOVA, F.S. - BOLSHAKOVA, S.V. 2017b. Inclusion as a Form of Social Inequality Overcoming in the Educational Environment. In: Man of India, vol. 97, n. 3. ISSN: 0025-1569

REUTOV, E.V. - TROSHIN, T.V. 2015. The Internet Practices and Information Preferences of the Population. In: Sociological researches, n. 4, pp.140-148. ISSN: 0132-1625

SHAPOVALOVA, I.C. 2015. The Influence of Internet Communication on the Behavior and Intellectual Development of Young People. In: Sociological research, n. 4, pp.148-151. ISSN: 0132-1625

SHVATCHKINA, L.A. - IGOSHEVA, M.A. - POLOZHENKOVA, Y.Y. 2016. Zenit Changes in Socio-Cultural Space of Russia in the Context of Processes of Modernization and Globalization. In: Humanitarian of the South of Russia, vol. 18, n. 2, pp.131-140. ISSN:2227-8656

TOYNBEE, A.A. 2002. Study of History. Transl. Moscow: Iris Press. ISBN: 5-81120063-3

ZHIVOTOVSKAYA, I.G. 2003. Europe Education System in the Context of Globalization: Problems and New Challenges. In: Actual problems of Europe, n. 3, pp.163-177. ISSN: 0235-5620

Words: 4568

Characters: 30457 (16,92 standard pages)

Assoc. Prof. Natalia A. Orekhovskaya, Doctor of Philosophy

Department of Sociology

Financial University under the Government of the Russian Federation

49 Leningradsky prospect

125993 Moscow

Russia

orehovskaya@yandex.ru 
Prof. Alexander A. Galushkin, PhD

Assoc. Prof. on International Laver

Department of Municipal Law

Peoples' Friendship University of Russia (RUDN University)

6 Miklukho-Maklaya Str.

117198, Moscow

Russia

alexander.galushkin@yandex.ru

Assoc. Prof. Elena V. Maleko, PhD

Department of Law and Cultural Studies

Nosov Magnitogorsk State Technical University

38 Lenina prospect

455000, Magnitogorsk

Russia

elena.maleko@yandex.ru

Assoc. Prof. Tatyana A. Bezenkova, PhD

Department of Social Work and Psychology-Pedagogical Education

Nosov Magnitogorsk State Technical University,

38 Lenina prospect

455000, Magnitogorsk

Russia

bezenkova@yandex.ru

Assoc. Prof. Natalya A. Plugina, PhD

Department of Applied and Theoretical Physics

Nosov Magnitogorsk State Technical University,

38 Lenina prospect

455000, Magnitogorsk

Russia

natalia2209@yandex.ru 